\title{
Numerical Simulation of the Gasoline Spray with an Outward-Opening Piezoelectric Injector: A Comparative Study of Different Breakup Models
}

\author{
Author, co-author (Do NOT enter this information. It will be pulled from participant tab in \\ MyTechZone) \\ Affiliation (Do NOT enter this information. It will be pulled from participant tab in MyTechZone)
}

Copyright $\odot 2018$ SAE International

\begin{abstract}
The outward-opening piezoelectric injector can achieve stable fuel/air mixture distribution and multiple injections in a single cycle, having attracted great attentions in direct injection gasoline engines. In order to realise accurate predictions of the gasoline spray with the outwardopening piezoelectric injector, the computational fluid dynamic (CFD) simulations of the gasoline spray with different droplet breakup models were performed in the commercial CFD software STAR-CD and validated by the corresponding measurements. The injection pressure was fixed at 180 bar, while two different backpressures ( 1 and 10 bar) were used to evaluate the robustness of the breakup models. The effects of the mesh quality, simulation timestep, breakup model parameters were investigated to clarify the overall performance of different breakup model in modeling the gasoline sprays. It is found that the tuned Reitz-Diwakar (RD) model shows robust performance under different backpressures and the spray penetration shows good agreement with the experimental measurements. However, the modified Kelvin-Helmholtz (KH) Rayleigh-Taylor (RT) model could not achieve good agreements with fixed model parameters at different backpressures. The tuned KHRT model at 1 bar backpressure shows much faster breakup process at 10 bar backpressure, leading to abnormal spray patterns and fuel vapor distributions. As there is no further tuning requirement for different backpressures, the RD model is found to be better in modeling the gasoline sprays from the outward-opening piezoelectric injector.
\end{abstract}

\section{Introduction}

The liquid fuel injection, atomization and spray formation are the key in-cylinder processes affecting the combustion and emission characteristics in the internal combustion engines. In order to achieve cleaner and more efficient combustion process in both direct injection (DI) spark ignition engine and compression ignition (CI) engine, the fuel spray characteristics and injection strategies have to be well optimised in order to achieve better fuel evaporation and fuel/air mixing process, as well as more complete combustion process.

Compared to the port fuel injection (PFI) engines, the gasoline direct injection (GDI) engines require more sophisticated controls on the fuel injection and fuel/air mixing process to achieve improved combustion performance. The outward-opening piezoelectric injectors, as shown in Figure 1, can produce a stable hollow-cone spray pattern with a shorter penetration and a recirculation zone at the

Page 1 of 12 spray tip, which minimises the wall wetting and deposit formation when applying to the GDI engines. The piezoelectric actuator also enables precise and flexible controls of the fuel injection rate and duration with rapid opening and closing for multiple injections, allowing significant fuel economy improvements of the spray-guided GDI engine compared to the throttled PFI engine [1]. The optical diagnostics and numerical modeling have been extensively used to understand the fuel injection, mixture formation and subsequent combustion process in advanced GDI engines [1]. Thanks to the development of computational fluid dynamic (CFD) techniques and the enhancement of computer performance, the multi-dimensional computational fluid dynamics (CFD) simulation has become a more effective and efficient tool to study and optimise the in-cylinder fuel injection, mixture formation and combustion process for GDI engines.
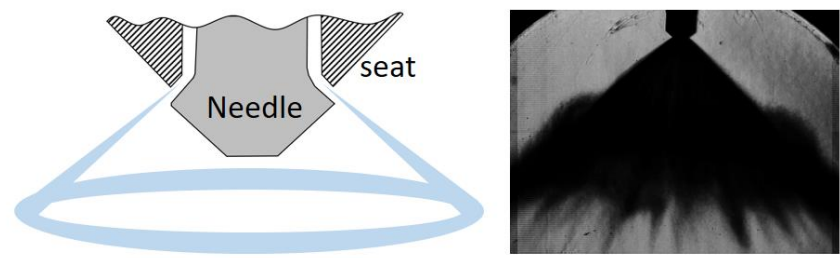

Figure 1.The schematic graph and spray image of the outward-opening piezoelectric injector.

In order to describe the fuel atomisation and breakup process, different spray models have been developed for CFD simulations. Reitz and Diwakar [2] presented the Reitz-Diwakar (RD) breakup model to calculate complex interactions between sprays and gas motions. Then, Reitz [3] presented the wave model by using the development of Kelvin-Helmholtz (KH) instabilities on the liquid jets. The Rayleigh-Taylor (RT) breakup model, proposed by Taylor [4], considers the unstable RT waves due to the rapid deceleration of the drops. The KHRT hybrid breakup model, consisting of both the KH and RT instability theories, was then proposed by Beale and Reitz [5] to predict both the diesel and gasoline sprays. O'Rourke and Amsden [6] presented the Taylor Analogy Breakup (TAB) model to calculate the droplet breakup for engine sprays.

In the real applications of these breakup models, extensive model calibration work has to be done to ensure accurate predictions of the atomisation and breakup process for different injectors at different operating conditions. Hossainpour and Binesh [7] predicted the incylinder spray atomisation and subsequent combustion process in a 
DI heavy-duty diesel engine by applying different droplet breakup models. The results indicated that the RD model overpredicted the spray tip penetration comparing with wave and KHRT models. In order to predict the diesel spray, Gao et al. [8] calibrated the WAVE breakup model by using a series of spray experiments with different orifice diameters, injection pressures, background gas densities and temperatures. It was found that the standard WAVE model with a fixed model parameter for breakup time cannot accurately predict the liquid length and spray penetration with different background temperatures. Specifically, they found the parameter for breakup time decreases with an increase in background temperature. Ren and Li [9] simulated the high-pressure diesel sprays against experimental observations with different breakup models and found that the modified KHRT breakup model (without the breakup length) gave the most reasonable predicted results in both engine simulation and high-pressure diesel spray simulation. For the standard KHRT model, the model parameter for the breakup length had a significant effect on the predictability of the model, and a fixed value of this parameter cannot provide a satisfactory result for different operation conditions. The TAB and RT breakup models cannot provide reasonable predictions for the characteristics of high-pressure sprays either. Brulatout et al. [10] compared the simulation results of the highpressure diesel sprays with RD and KHRT models and demonstrated the important interaction between model parameters on the simulation results for both models.

In terms of the gasoline spray, Han et al. [11] and Fan et al. [12] applied the sheet atomisation model with the TAB breakup model to study the spray atomisation and air-fuel mixing in a direct-injection spark-ignition engine with the pressure-swirl injector. Kong et al. [13] also successfully applied the liquid sheet breakup model and the TAB droplet breakup model to predict the gasoline hollow-cone sprays. Dempsey and Reitz [14] applied the standard KHRT hybrid breakup model [5] to predict the spray process in a gasoline compression ignition engine with the multi-hole injector. Then, Malaguti et al. [15] modelled the gasoline spray from a multi-hole injector by using a modified atomisation model and the KHRT breakup model. Dam and Rutland [16] predicted the gasoline sprays from a multi-hole injector at various background temperatures (400 $900 \mathrm{~K}$ ) and densities (3-9 kg/m3) with the standard KHRT breakup model and found that it was necessary to adjust breakup model parameters, including the break-up length, as functions of the density ratio in order to accurately simulate the large-scale vapor mixing. Wang et al. [17-19] and Bonatesta et al. [20] calibrated the RD model to predict the gasoline spray and combustion process in wall-guided DI gasoline engines with the multi-hole injector. Sim et al. [21] modeled the gasoline spray from an outward-opening piezoelectric injector with the modified KHRT breakup model, and the initial Sauter mean diameter (SMD) values were varied in order to validate against the measurements under different background conditions.

As shown by the above literature review, there are only a few papers covering the modeling of gasoline spray from the outward-opening piezoelectric injector. In this study, the comprehensive simulations were performed with the RD and the modified KHRT models available in the commercial software STAR-CD in order to accurately model the gasoline sprays from the outward-opening piezoelectric injector under different background pressures. The effects of the mesh quality, simulation timestep, breakup model parameters on the spray were analysed in detail to understand the overall performances of different breakup models.

\section{Numerical models}

In this study, the simulations were performed with the commercial CFD software STAR-CD [22]. The Reynolds-Averaged Navier Stokes (RANS) approach was applied with RNG k- $\varepsilon$ turbulence model. The heat transfer was implemented through the general form of the enthalpy conservation equation for the fluid mixture [23]. The Angelberger wall function [24] was used for the simulation of the wall heat transfer. In order to depict the liquid fuel injection process from the outward-opening piezo injector, the nozzle was defined by setting the nozzle hole diameter, inner and outer cone angles. The coupled Lagrangian approach was applied with the explicitly defined parent computational parcels to initialise the atomised droplets. The droplet size distribution of the initial parent parcels was determined by Rosin-Rammler functions [25] and the model constants X and $\mathrm{q}$ were fixed at $0.18 \mathrm{~mm}$ and 3.5 , respectively. The formulations proposed by El Wakil et al. [26] and Ranz-Marshall [27] were used to predict the heat transfer and evaporation of droplets in the simulations. The O' Rourke model [22] and Bai model [28] were adopted to consider the inter-droplet collision and wall impingement, respectively. In order to predict the gasoline spray droplet breakup process, the RD [2] and the modified KHRT [22] models were applied and validated in this study. The above numerical models are summarized in Table 1.

Table 1. Numerical models

\begin{tabular}{|l|l|}
\hline Turbulence model & RNG k- $\varepsilon$ \\
\hline Nozzle model & Explicitly defined \\
\hline Initial droplet distribution & Rosin-Rammler \\
\hline Droplet collision model & O' Rourke model \\
\hline Droplet-wall interaction model & Bai \\
\hline Droplet breakup model & Modified KHRT/Reitz-Diwakar \\
\hline
\end{tabular}

The Pressure-Implicit with Splitting of Operators (PISO) algorithm was used to solve the equations. The equations of momentum, turbulent kinetic energy and turbulence dissipation were discretized with the monotone advection and reconstruction scheme (MARS). The upwind differencing scheme (UD) and central differencing scheme (CD) were applied to discretize the temperature and density equations, respectively. The residual tolerance for the momentum, turbulent kinetic energy and turbulence dissipation was set at 0.01 while the residual tolerance for pressure and temperature was set at 0.001 to achieve good compromise between convergence and computational time.

\section{Reitz-Diwakar (RD) breakup model}

In the RD breakup model [2, 22], there are two regimes, bag breakup and stripping breakup, controlling the breakup process of the droplets due to the aerodynamic forces. In the bag breakup regime, the nonuniform pressure field around the droplet leads to the disintegration of the droplet when its surface tension forces are overcome. In the stripping breakup regime, the liquid is sheared or stripped from the droplet surface. The breakup rate of the droplet for each regime can be calculated by equation (1),

$\frac{d D_{d}}{d t}=-\frac{\left(D_{d}-D_{d, \text { stable }}\right)}{\tau_{b}}$ 
where $D_{d, \text { stable }}$ is the stable droplet diameter, $\tau_{b}$ is the characteristic time scale, $D_{d}$ is the instantaneous droplet diameter. The criteria and time scales for each breakup regime are described as following.

In the bag breakup regime, the instability is determined by a critical value of the Weber number (We),

$\mathrm{We} \equiv \frac{\rho\left|u-u_{d}\right|^{2} D_{d}}{2 \sigma_{d}} \geq C_{b 1}$

where $\rho$ is the ambient density, $u$ is the velocity of ambient gas, $u_{d}$ is the velocity of droplet, $\sigma_{d}$ is the surface tension coefficient, and $C_{b 1}$ is the empirical coefficient with a value in the range of 3.6-8.4. The stable droplet size is that which satisfies the equality in the above equation. The associated characteristic time is,

$\tau_{b}=\frac{C_{b 2} \rho_{d}{ }^{1 / 2} D_{d}{ }^{3 / 2}}{4 \sigma_{d}^{1 / 2}}$

where $\rho_{d}$ is the droplet density, and $C_{b 2} \approx \pi$.

The criterion for the onset of stripping breakup regime is,

$\frac{W e}{\sqrt{R e_{d}}} \geq C_{s 1}$

where $R e_{d}$ is the droplet Reynolds number and $C_{s 1}$ is a coefficient with the value of 0.5 . The characteristic time scale $\tau_{b}$ for this regime is,

$\tau_{b}=\frac{C_{s 2}}{2}\left(\frac{\rho_{d}}{\rho}\right)^{1 / 2} \frac{D_{d}}{\left|u-u_{d}\right|}$

where the empirical coefficient $C_{S 2}$ is in the range of 2-20.

\section{KHRT breakup model}

In this study, the modified KHRT model without the breakup length was implemented. The KHRT droplet breakup model was proposed by Patterson and Reitz [29]. This breakup model introduces the competition of the droplet breakup due to $\mathrm{KH}$ aerodynamic instabilities and RT instabilities, and the one predicting the fastest onset of an instability dominates the breakup process. The detailed description can be found in [22,29], only the brief introduction of the model is shown here.

In the $\mathrm{KH}$ breakup process, the small droplets are shed from the parent computational parcel to form a new parcel. The parent droplet with the radius larger than the wavelength $\Lambda_{K H}$ of the growing unstable surface wave will break into a new parent and child droplet pair and the diameter $\left(D_{S}\right)$ of the stable child droplet is calculated by equation (6),

$D_{s}=2 B_{0} \Lambda_{K H}$

where $B_{0}$ is a model constant with default value 0.61 . The rate of change of the parent droplet diameter $D_{d}$ is given by equation (7),

$\frac{d D_{d}}{d t}=-\frac{D_{d}-D_{d, \text { stable }}}{\tau_{K H}}$ where the characteristic breakup timescale $\tau_{K H}$ is calculated using the expression suggested by Reitz [3] and Senecal et al. [30],

$\tau_{K H}=\frac{3.726 B_{1} D_{d} / 2}{\Lambda_{K H} \Omega_{K H}}$

where $B_{1}$ is a model constant with the range of $10-60$, and $\Omega_{K H}$ is the growth rate of the fastest growing wave. Detailed expressions for the latter can be found in the original publication by Patterson and Reitz [29]. As the diameter of the parent droplet reduces, its total mass decreases. If the difference between the original and the new parcel mass is greater than a given threshold (typically $3 \%$ of the original mass), the smaller droplets are shed off to form a new parcel.

In the RT breakup process, the droplet diameter $D_{d}$ should be larger than the wavelength $\Lambda_{R T}$ of the fastest growing wave, scaled by a constant $C_{3}$ with the range of 0.1-1.0,

$D_{d}=C_{3} \Lambda_{R T}$

Furthermore, sufficient time greater than the RT breakup timescale $\tau_{R T}$ must have elapsed since the last RT breakup. $\Lambda_{R T}$ is obtained by calculating the corresponding wave number $k_{R T}=2 \pi / \Lambda_{R T}$ which maximizes the growth rate given by,

$\omega(k)=-k^{2}\left(\frac{\mu_{d}+\mu}{\rho_{d}+\rho}\right)+\sqrt{k\left(\frac{\rho_{d}-\rho}{\rho_{d}+\rho}\right) a-\frac{k^{3} \sigma}{\rho_{d}+\rho}+k^{4}\left(\frac{\mu_{d}+\mu}{\rho_{d}+\rho}\right)^{2}}$

where $\mu$ is ambient dynamic viscosity, $\mu_{d}$ is the fuel droplet dynamic viscosity, $a$ is the acceleration or deceleration of the droplet, while

$\tau_{R T}=\frac{C_{\tau}}{\omega_{R T}}$

$\omega_{R T}=\omega\left(k_{R T}\right)$

where $C_{\tau}$ is a model constant often set equal to 1 .

\section{Simulation conditions and meshes}

The predicted gasoline fuel injection and spray formation processes will be validated against the spray measurements in a constant volume vessel. The gasoline injection pressure and fuel temperature were 180 bar and $293 \mathrm{~K}$, respectively. The background temperature was fixed at $293 \mathrm{~K}$, and two background pressures (i.e. 1 bar and 10 bar) were measured. The background gas in the chamber was pure nitrogen $\mathrm{N}_{2}$. The Schlieren method was applied to measure the spray process. Theoretically, both liquid and vapor can be visualized with the Schlieren methods. As the background temperature in the constant volume vessel was $293 \mathrm{~K}$, the evaporation of the liquid fuel should be weak. In the simulations, all these initial and boundary conditions were kept the same as the measurements.

The gasoline fuel was adopted in the measurements and the injection duration was fixed around $1.0 \mathrm{~ms}$. The iso-octane was applied in the simulation. But the corresponding properties of the liquid droplets, including the density, surface tension coefficient, viscosity and so on, were then modified according to the real gasoline used in the measurements. The properties of the evaporated fuel vapor were fixed as the same with the iso-octane. 
The simulation meshes of the constant volume vessel with different grid sizes were generated to perform the mesh sensitivity study. As shown in Figure 2, the grid size of the spray zone was increased from $0.5 \mathrm{~mm}$ to $1 \mathrm{~mm}$ and the grid size of remaining region was fixed at 4 $\mathrm{mm}$ in order to reduce the computational time. The coarse mesh with the grid size of $1.5 \mathrm{~mm}$ is uniform throughout the simulation region. For simplicity, the mesh size mentioned in this study refers to the mesh size of spray zone. It should be noted that the injector geometry was not meshed for the baseline cases. As the near-nozzle geometry showed impacts on the large eddy simulations [16], a new mesh, as shown in Figure 2 ( $2^{\text {nd }}$ row), was generated by directly removing the cells above the injector nozzle from the baseline mesh with $1.0 \mathrm{~mm}$ mesh size in order to examine the impact of the injector geometry on the simulation results.

The baseline value of the simulation timestep was $0.0025 \mathrm{~ms}$ and two alternative values of 0.001 and $0.005 \mathrm{~ms}$ were also evaluated to clarify the sensitivity of the simulation results to timestep.

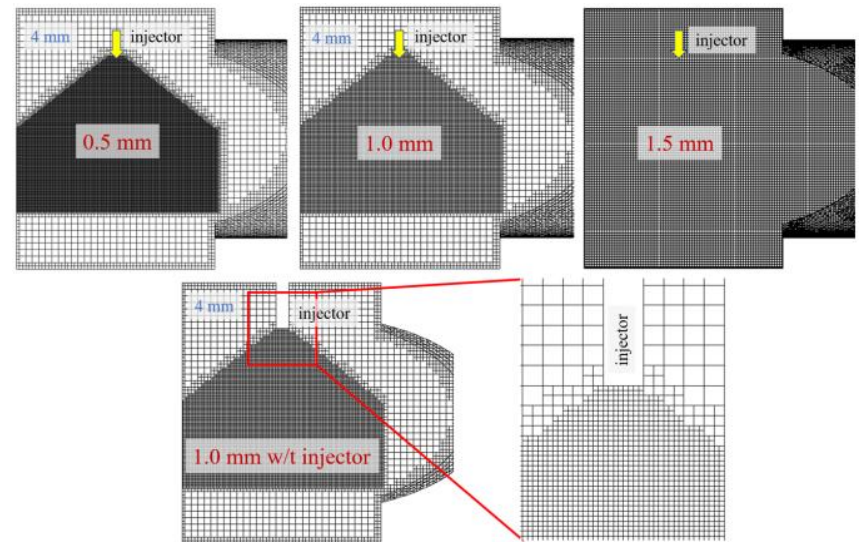

Figure 2. Simulation meshes with different mesh sizes ( $1^{\text {st }}$ row $)$ and the mesh with consideration of the geometry of the injector ( $2^{\text {nd }}$ row $)$.

\section{Results and discussion}

\section{Effect of the simulation mesh}

Figure 3 shows the effect of the mesh size on the spray penetration with KHRT model under 1 bar and 10 bar backpressures. The model constants were fixed with $\mathrm{B}_{0}=0.61, \mathrm{~B}_{1}=40, \mathrm{C}_{3}=0.5$ and $\mathrm{C}_{\tau}=1$. It should be noted that the experimental spray tip penetration was defined as the distance between the lowest edge of the injector nozzle and the vertically farthest point of the visualized spray plume with Schlieren method. The spray tip penetration in the simulation was defined as the distance between the injector tip position (same with experiment) and the spray front with $98 \%$ of the total injected fuel mass in the vertical direction.

At 1 bar backpressure, the mesh size of $1.5 \mathrm{~mm}$ shows longer penetration at the beginning stage but increases slowly and shows shorter penetration after $0.4 \mathrm{~ms}$. Overall, the mesh size of $0.5 \mathrm{~mm}$ and $1.0 \mathrm{~mm}$ show similar penetration throughout the injection events. As shown in Figure 4 (a), the predicted spray patterns with the KHRT model are similar to the optical measurements. However, with the increase of the mesh size, the curling of the droplets at the recirculation region gradually disappears, indicating the weaker droplet breakup process with a large mesh size.

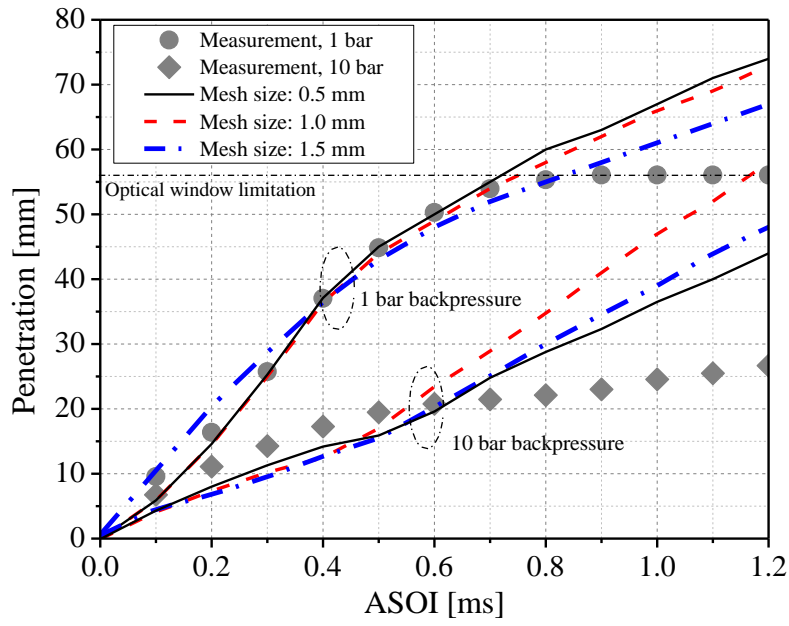

Figure 3. Effect of mesh size on the spray penetration with KHRT model ( $\mathrm{B}_{0}$ $=0.61, \mathrm{~B}_{1}=40, \mathrm{C}_{3}=0.5$ and $\mathrm{C}_{\tau}=1$ ).
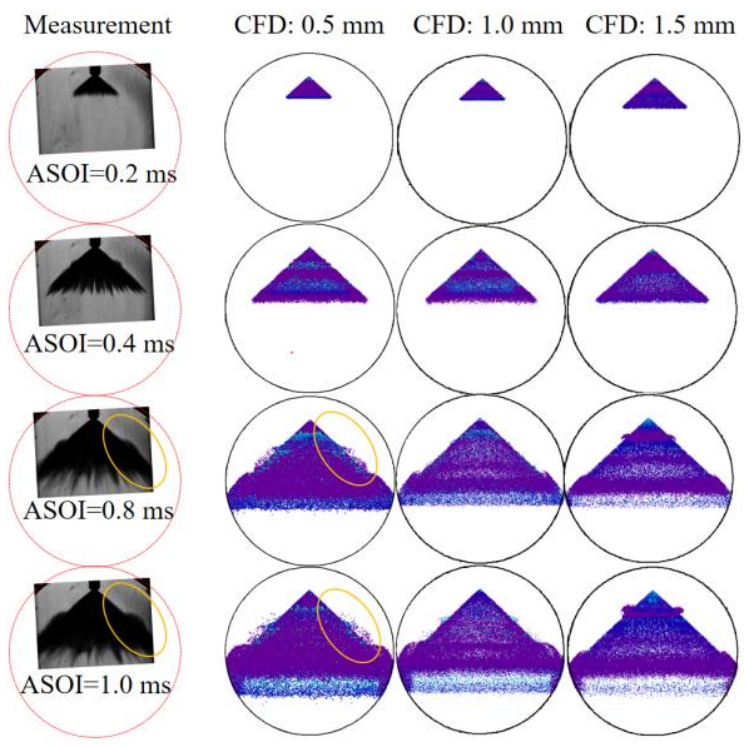

(a) 1 bar backpressure.

Measurement CFD: $0.5 \mathrm{~mm} \quad$ CFD: $1.0 \mathrm{~mm} \quad$ CFD: $1.5 \mathrm{~mm}$
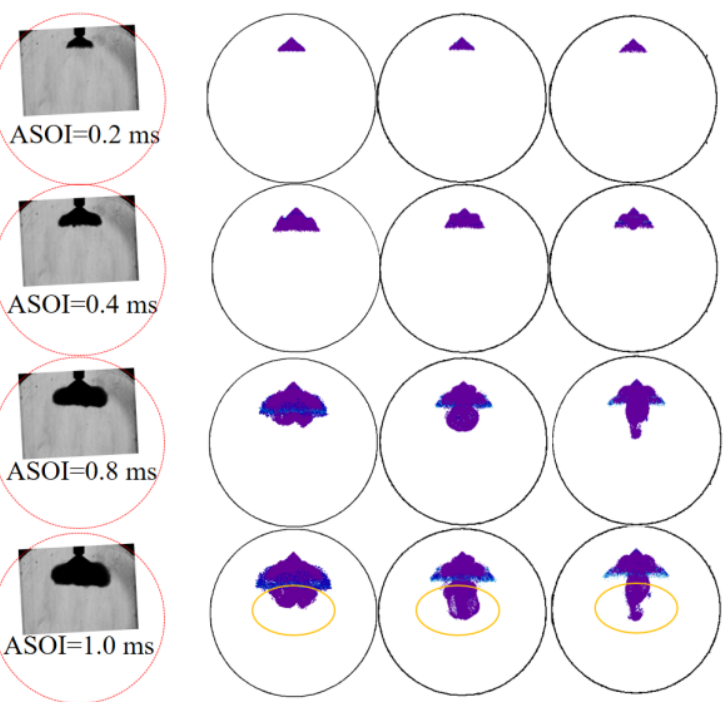

(b) 10 bar backpressure. 
Figure 4. Effect of mesh size on the droplet distribution at (a) 1 bar and (b) 10 bar back pressure with KHRT model $\left(B_{0}=0.61, B_{1}=40, C_{3}=0.5\right.$ and $\left.C_{\tau}=1\right)$.

At 10 bar backpressure, the mesh size of $0.5 \mathrm{~mm}$ shows slightly longer penetration at the beginning stage (before $0.5 \mathrm{~ms}$ ), as shown in Figure 3 . Then it is interesting to find that the $1.5 \mathrm{~mm}$ mesh size produces similar penetration with that of $0.5 \mathrm{~mm}$ mesh size, while 1.0 $\mathrm{mm}$ mesh size produces much longer penetration after $0.5 \mathrm{~ms}$. Most importantly, all three predicted penetrations are significantly longer than the measurements after $0.5 \mathrm{~ms}$. The main reason can be attributed to the abnormal spray patterns under the main spray umbrella with KHRT model, as shown in Figure 4 (b). With the increase of the mesh size, more droplets are transported to the downstream of the main spray jets. This abnormal phenomenon was also reported by Dam and Rutland [16] with KHRT model.

Figure 5 shows the effect of the mesh size on the global Sauter mean diameter (SMD) evolutions at 1 bar and 10 bar backpressures with the KHRT model. The global SMD was calculated by equation (13),

$\operatorname{SMD}=\frac{\sum_{i} D_{d}{ }^{3} n_{i}}{\sum_{i} D_{d}{ }^{2} n_{i}}$

where $D_{d}$ is the droplet diameter and $n_{i}$ is the number of droplets in parcel $i$.

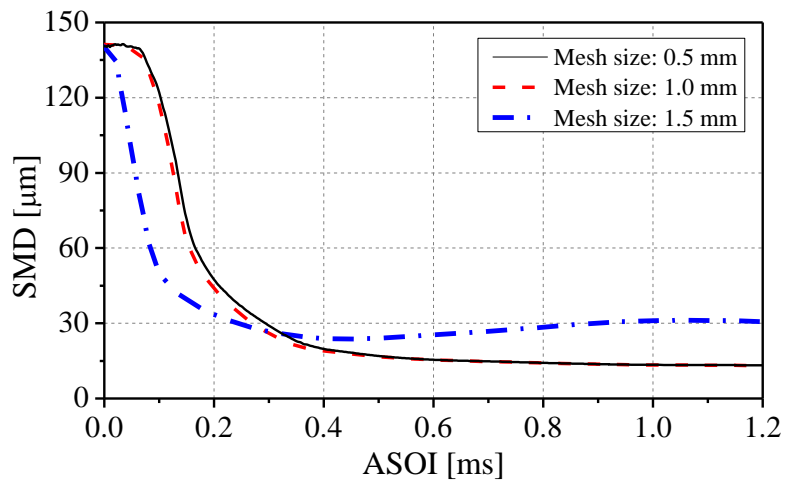

(a) 1 bar backpressure.

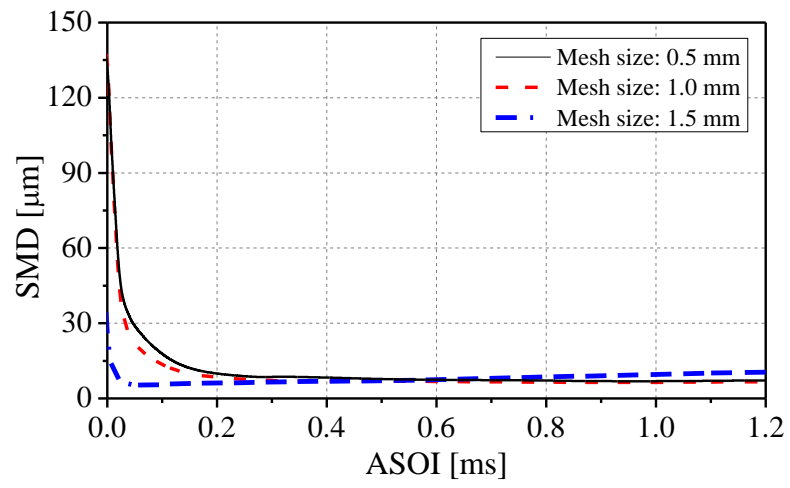

(b) 10 bar backpressure

Figure 5. Effect of mesh size on the SMD at (a) 1 bar and (b) 10 bar back pressure with KHRT model $\left(B_{0}=0.61, B_{1}=40, C_{3}=0.5\right.$ and $\left.C_{\tau}=1\right)$.

As shown in Figure 5, $0.5 \mathrm{~mm}$ and $1.0 \mathrm{~mm}$ mesh sizes show similar traces of the SMD evolutions at both 1 bar and 10 bar backpressures. For the coarse mesh with $1.5 \mathrm{~mm}$ mesh size, the breakup is much stronger at the very beginning stage. which is much more significant at 10 bar backpressure. The enhanced early breakup process leads to the transportation of more small droplets to the downstream region under the main spray umbrella, leading to the abnormal spray patterns as seen in Figure 4

Figure 6 shows the impact of the mesh size on the spray penetration with the RD model. The mesh size of $1.5 \mathrm{~mm}$ also produces longer penetration at the early stage but shorter penetration at later stage at both 1 bar and 10 bar backpressures. The difference of the penetration between $1.0 \mathrm{~mm}$ and $0.5 \mathrm{~mm}$ mesh sizes is very small at 1 bar backpressure. As the backpressure increases to 10 bar, the difference of penetration between $1.0 \mathrm{~mm}$ and $0.5 \mathrm{~mm}$ mesh size gradually becomes larger after $0.3 \mathrm{~ms}$. Overall, both $1.0 \mathrm{~mm}$ and 0.5 $\mathrm{mm}$ mesh sizes could well reproduce the measured penetration at both backpressures with the RD model.

Figure 7 compares the spray droplet distributions at 1 bar and 10 bar backpressures with RD model. Similarly, the increased mesh size leads to less curling structures of the droplets at the recirculation region. The abnormal spray pattern, as seen in Figure 4 (b) with the KHRT model, is avoided at 10 bar backpressure with the RD model. Only the coarse mesh with $1.5 \mathrm{~mm}$ mesh size produces obvious downstream droplet distribution. Overall, the spray patterns with the $\mathrm{RD}$ model and mesh size of $1.0 \mathrm{~mm}$ and $0.5 \mathrm{~mm}$ agree well with the optical measurements.

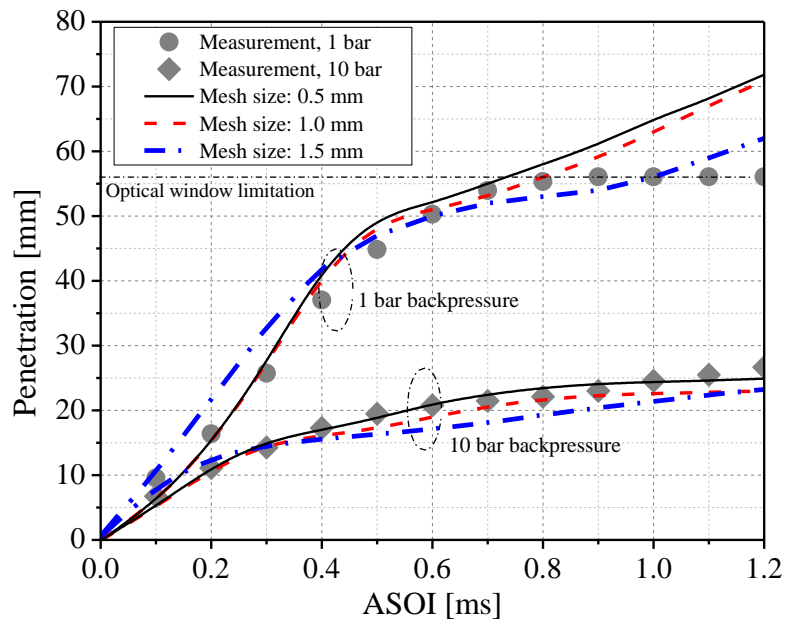

Figure 6. Effect of mesh size on the spray penetration with Reitz-Diwakar model, $\left(\mathrm{C}_{\mathrm{b} 1}=8.4, \mathrm{C}_{\mathrm{b} 2}=\pi, \mathrm{C}_{\mathrm{s} 1}=0.5\right.$ and $\left.\mathrm{C}_{\mathrm{s} 2}=20\right)$.

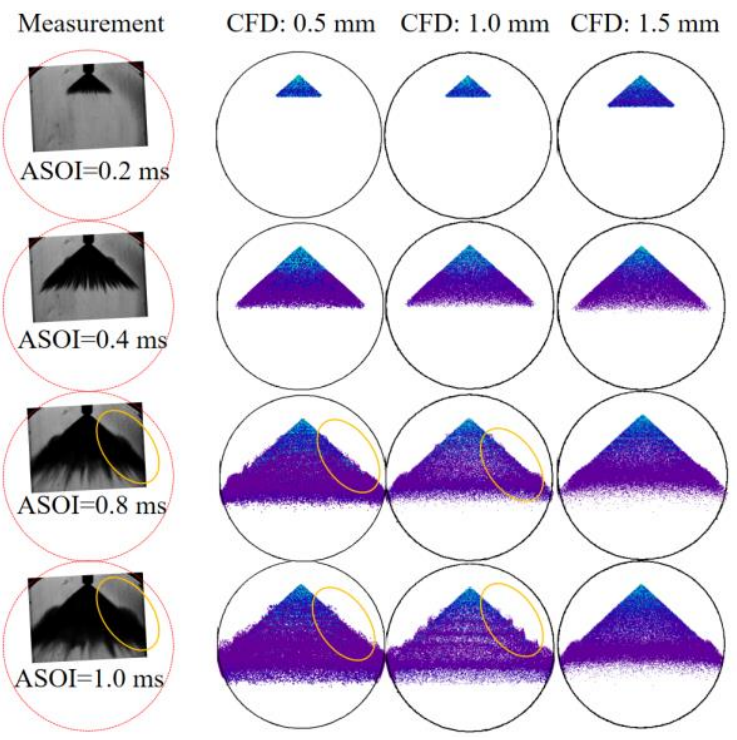

(a) 1 bar backpressure. 


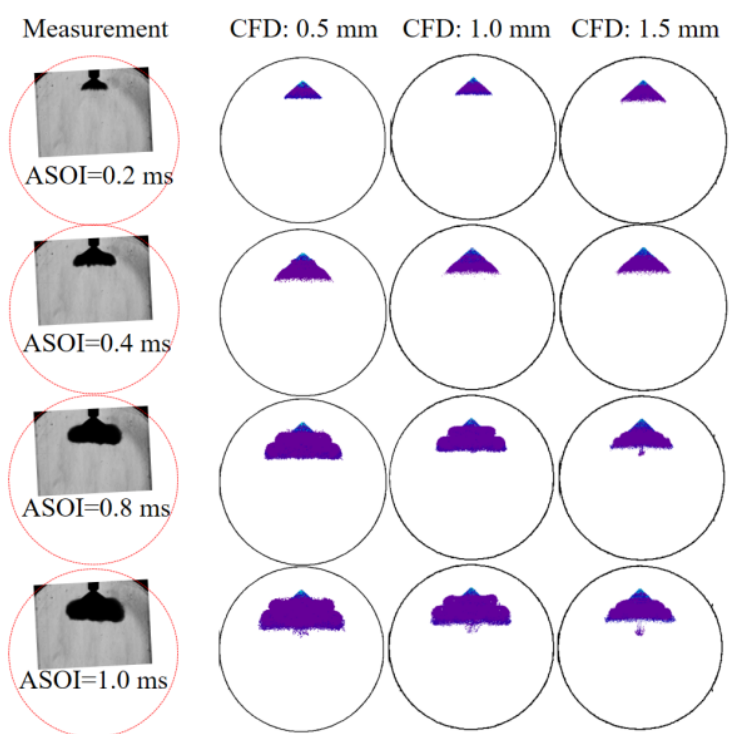

(b) 10 bar backpressure.

Figure 7. Effect of mesh size on the droplet distribution at (a) 1 bar and (b) 10 bar backpressures with Reitz-Diwakar model, $\left(\mathrm{C}_{\mathrm{b} 1}=8.4, \mathrm{C}_{\mathrm{b} 2}=\pi, \mathrm{C}_{\mathrm{s} 1}=0.5\right.$ and $\mathrm{C}_{\mathrm{s} 2}=20$ ).

As shown in Figure 8, the coarse mesh with $1.5 \mathrm{~mm}$ mesh size also enhances the early breakup process, leading to faster decrease of the SMD after the injection. But it is found that the final SMD at the end of injection is higher for the coarse mesh than the fine meshes. The SMD evolutions with $1.0 \mathrm{~mm}$ and $0.5 \mathrm{~mm}$ mesh sizes are almost the same at both backpressures.

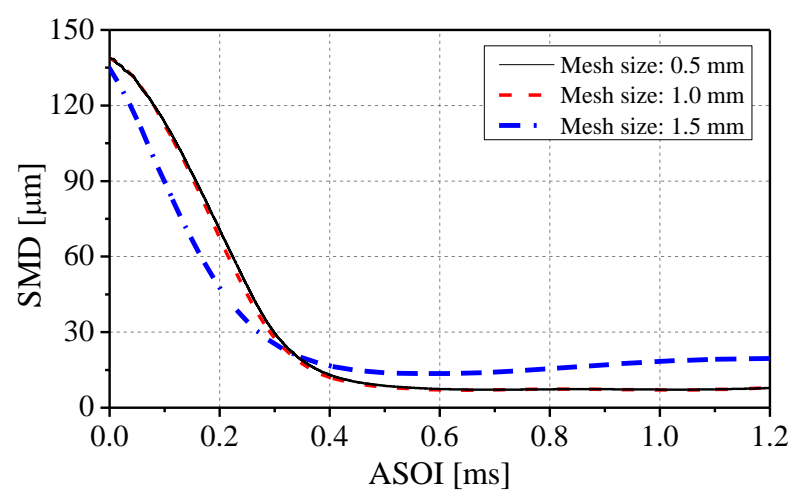

(a) 1 bar backpressure.

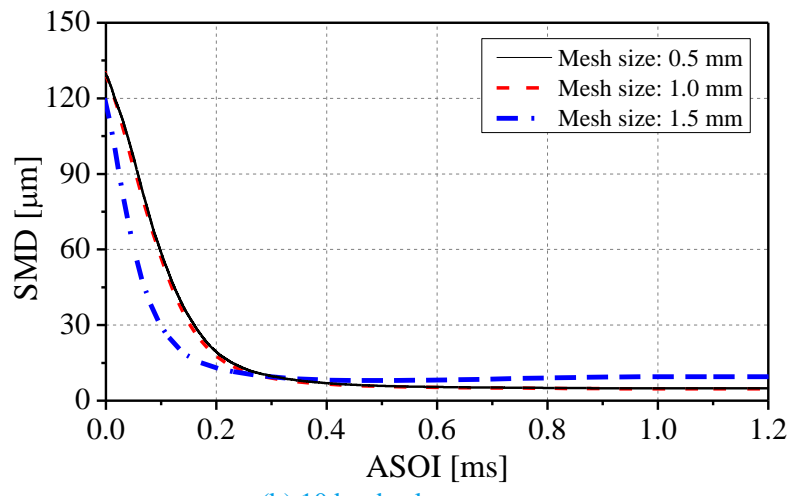

(b) 10 bar backpressure.

Figure 8. Effect of mesh size on the SMD at (a) 1 bar and (b) 10 bar backpressures with Reitz-Diwakar model, $\left(\mathrm{C}_{\mathrm{b} 1}=8.4, \mathrm{C}_{\mathrm{b} 2}=\pi, \mathrm{C}_{\mathrm{s} 1}=0.5\right.$ and $\mathrm{C}_{\mathrm{s} 2}=20$ ).

\section{Page 6 of 12}

The simulations with the injector tip geometry show little impact on the penetration at 1 bar backpressure with KHRT model, as shown in Figure 9. Although the penetration at 10 bar backpressure is slightly changed by considering the injector tip geometry in the mesh, there is no improvement of the spray patter with the KHRT model. The SMD is even reduced at the end of injection if considering the injector geometry, and the abnormal downstream droplet distribution is still existing, as shown in Figure 10. Figure 11 shows that there is little impact of the injector tip geometry on the penetration with RD model at both 1 bar and 10 bar backpressures.

Based on the above study, the mesh size of the $1.0 \mathrm{~mm}$ was used for the following study in order to reduce the computational time.

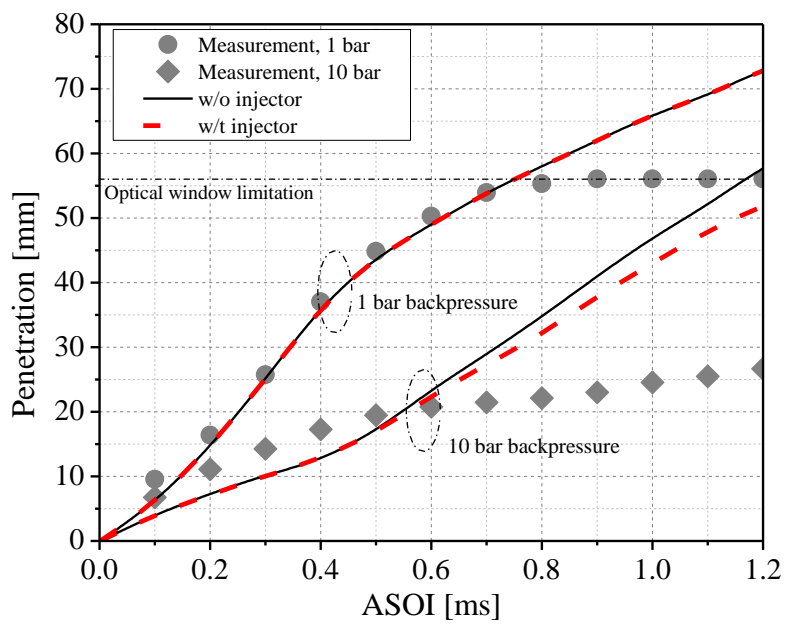

Figure 9. Comparison of the spray penetration w/o and w/t injector geometry in the mesh (KHRT model: $\mathrm{B}_{0}=0.61, \mathrm{~B}_{1}=40, \mathrm{C}_{3}=0.5$ and $\mathrm{C}_{\tau}=1$ ).

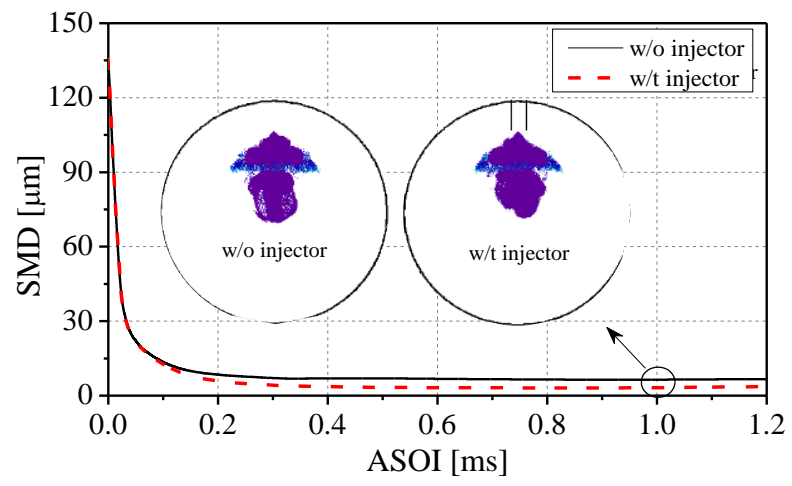

Figure 10. The SMD and droplet distribution (@ $1 \mathrm{~ms}$ ) with the mesh w/t and w/o injector geometry at 10 bar back pressure (KHRT model: $\mathrm{B}_{0}=0.61, \mathrm{~B}_{1}=$ $40, \mathrm{C}_{3}=0.5$ and $\left.\mathrm{C}_{\tau}=1\right)$. 


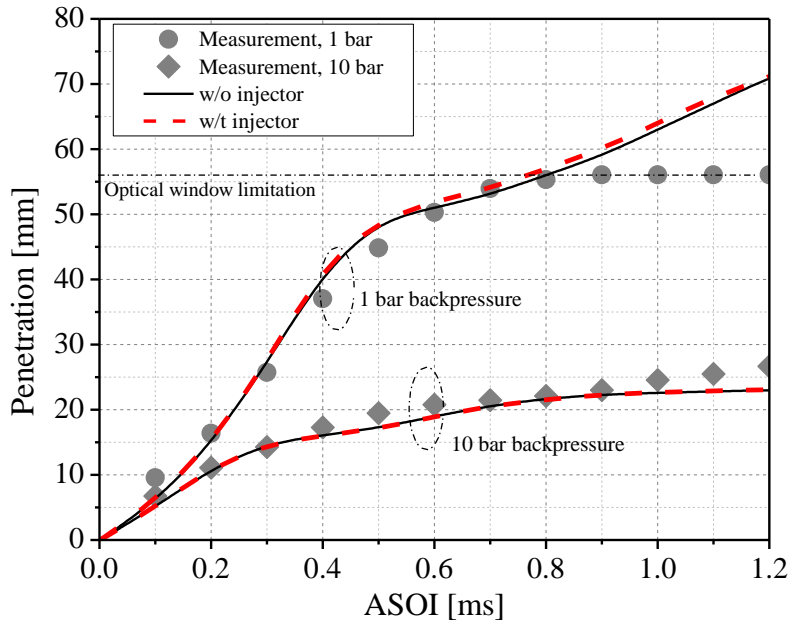

Figure 11. Comparison of the spray penetration $w / o$ and $w / t$ injector geometry in the mesh (Reitz-Diwakar model: $\mathrm{C}_{\mathrm{b} 1}=8.4, \mathrm{C}_{\mathrm{b} 2}=\pi, \mathrm{C}_{\mathrm{s} 1}=0.5$ and $\mathrm{C}_{\mathrm{s} 2}=20$ ).

\section{Effect of simulation timestep}

Figure 12 and Figure 13 compare the effect of the simulation timestep on the spray penetrations with KHRT and RD model, respectively. It is found that there is only slight impact of the adopted three timesteps on the spray penetrations under 1 bar backpressure, as well as the spray patterns and SMD evolutions (not shown here for simplicity). As the back pressure increases to $10 \mathrm{bar}$, the difference of the penetrations with different timesteps become larger but the penetrations with the intermediate timestep $(\Delta \mathrm{t}=0.0025 \mathrm{~ms})$ still agree well with the results with the shortest timestep $(\Delta \mathrm{t}=0.001 \mathrm{~ms})$. Therefore, the intermediate timestep with $\Delta \mathrm{t}=0.0025 \mathrm{~ms}$ was applied as the baseline value in this study.

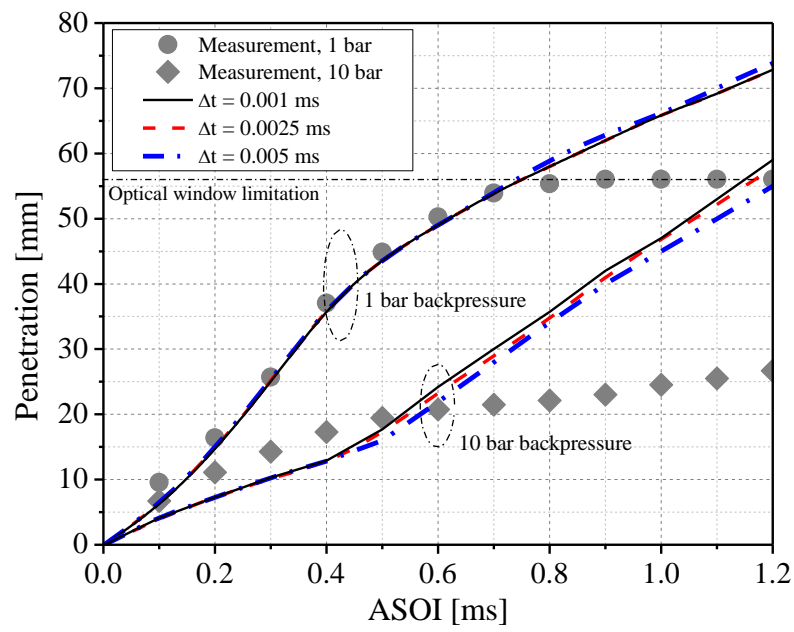

Figure 12. Effect of simulation time step on the spray penetration with KHRT model $\left(\mathrm{B}_{0}=0.61, \mathrm{~B}_{1}=40, \mathrm{C}_{3}=0.5\right.$ and $\left.\mathrm{C}_{\mathrm{r}}=1\right)$.

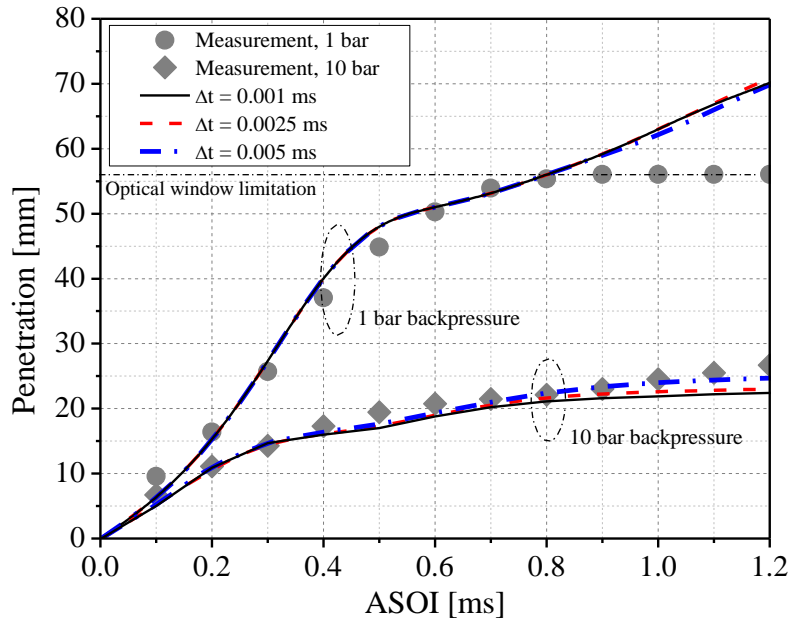

Figure 13. Effect of simulation time step on the spray penetration with ReitzDiwakar model, $\left(\mathrm{C}_{\mathrm{b} 1}=8.4, \mathrm{C}_{\mathrm{b} 2}=\pi, \mathrm{C}_{\mathrm{s} 1}=0.5\right.$ and $\left.\mathrm{C}_{\mathrm{s} 2}=20\right)$.

\section{Effect of model parameters of KHRT model}

In this section, the effect of the model tuning parameters is examined to understand the potential of the breakup model to accurately predict the gasoline sprays from the outward-opening piezoelectric injector. As detailed in the Numerical model section, the tuning parameters for KHRT model were $B_{1}$ and $C_{3}$, the parameters $B_{0}$ and $C_{\tau}$ were fixed at 0.61 and 1 respectively.

Figure 14 shows the impact of KHRT model parameter $\mathrm{B}_{1}$ on the spray penetration and SMD at 1 bar backpressure. As shown in the figure, the parameter $\mathrm{B}_{1}$ shows little impact on the initial breakup process, and the overall SMD before $0.1 \mathrm{~ms}$ is unaffected by $\mathrm{B}_{1}$. As $\mathrm{B}_{1}$ increases from 20 to 60 , the SMD after $0.1 \mathrm{~ms}$ gradually increases with $\mathrm{B}_{1}$ due to weaker breakup process. As a result, it is found that the penetration gradually increases with B1 after $0.2 \mathrm{~ms}$.

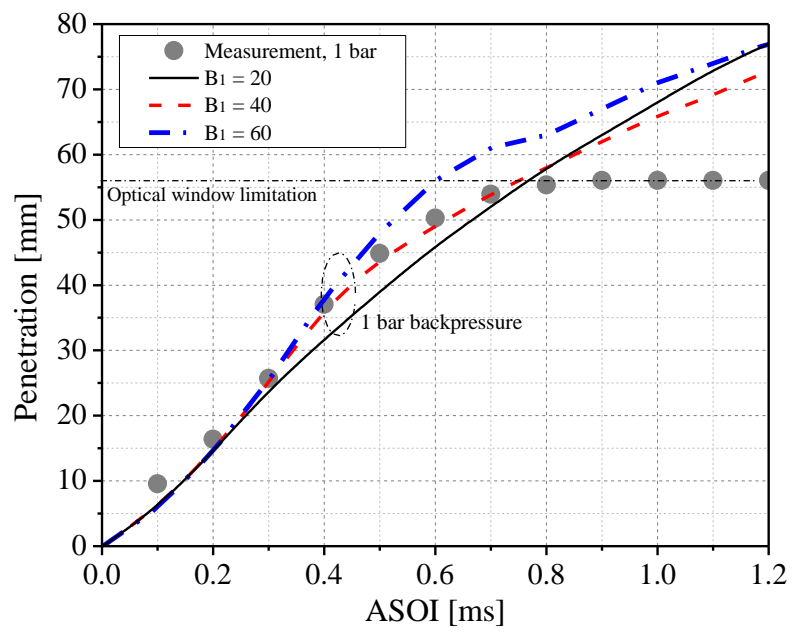

(a) Spray penetration. 


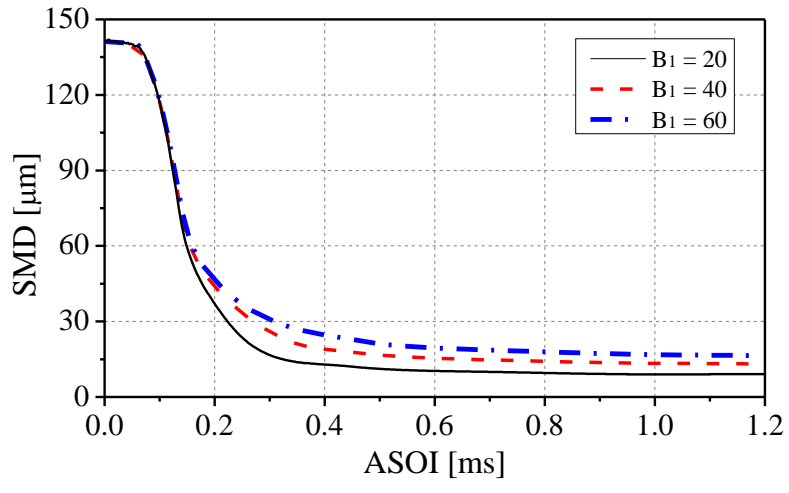

(b) Evolution of SMD.

Figure 14. Effect of constant $\mathrm{B}_{1}$ on (a) spray penetration and (b) SMD with KHRT model $\left(\mathrm{B}_{0}=0.61, \mathrm{C}_{3}=0.5\right.$ and $\left.\mathrm{C}_{\tau}=1\right)$.

In comparison, the model parameter $\mathrm{C}_{3}$ shows more significant impact on the initial breakup process, as indicated by the SMD evolutions shown in Figure 15 (b). As $\mathrm{C}_{3}$ decreases from 0.8 to 0.2, the reduction of SMD becomes much faster just after the start of injection, leading to shorter penetration at very early stage and throughout the whole injection event. Therefore, the parameter $\mathrm{C}_{3}$ is much more influential on the spray process than $\mathrm{B}_{1}$.

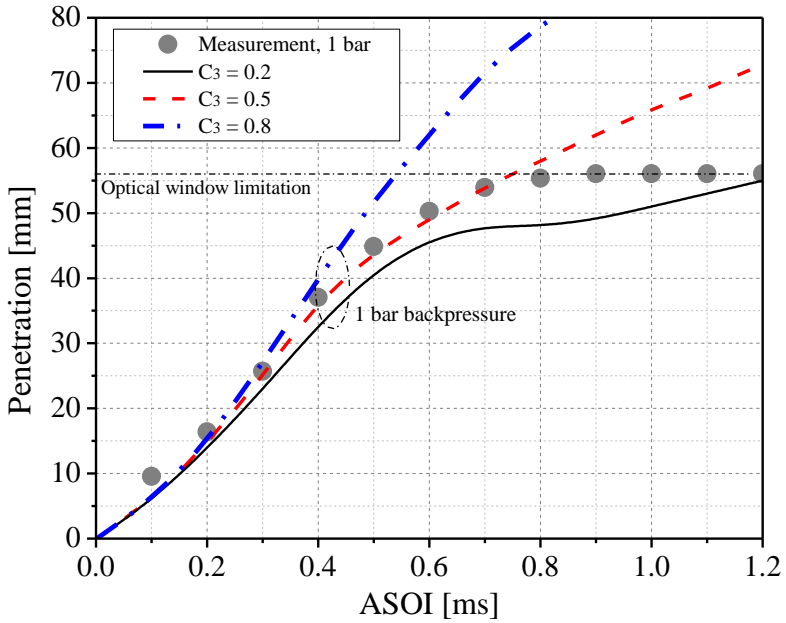

(a) Spray penetration

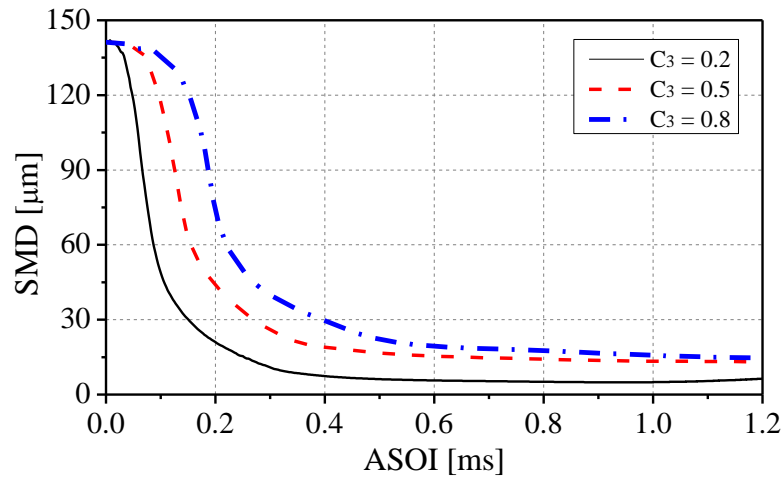

(b) Evolution of SMD.

Figure 15. Effect of constant $C_{3}$ on (a) spray penetration and (b) SMD with KHRT model $\left(\mathrm{B}_{0}=0.61, \mathrm{~B}_{1}=40\right.$ and $\left.\mathrm{C}_{\tau}=1\right)$.

Page 8 of 12
Figure 16 shows the validated spray penetration traces and SMD results at 1 bar and 10 bar backpressures respectively. The corresponding model parameters are also shown in the figures. It is found that the KHRT model could not accurately predict the spray process at two backpressures with fixed model parameters. The first parameter set with $\mathrm{B}_{1}=40$ and $\mathrm{C}_{3}=0.5$ could reproduce the spray penetration at 1 bar backpressure very well. But as the backpressure increases to 10 bar, the breakup process is significantly enhanced at the very beginning stage after the injection, as indicated by the SMD evolution shown in Figure 16 (c). As the result, the early penetration before $0.5 \mathrm{~ms}$ is shorter than the measurement while the later penetration is significantly higher than the measurement.

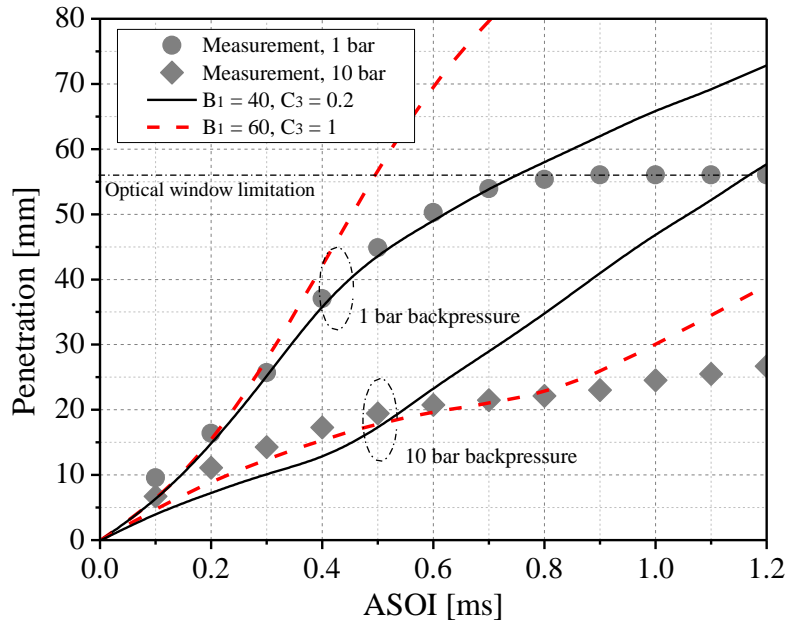

(a) Spray penetration.

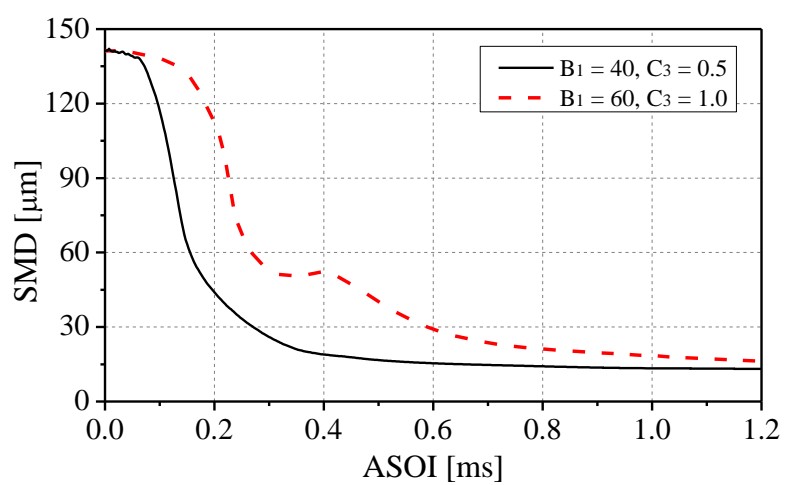

(b) Evolution of SMD with 1 bar backpressure.

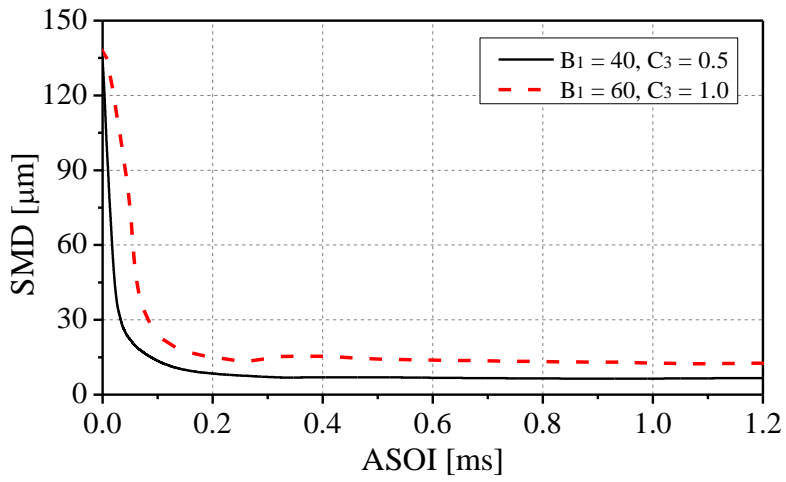

(c) Evolution of SMD with 10 bar backpressure

Figure 16. Comparison of the (a) spray penetration, (b) SMD at 1 bar backpressure and (c) SMD at 10 bar backpressure with different $\mathrm{B}_{1}$ and $\mathrm{C}_{3}$ (KHRT model: $\mathrm{B}_{0}=0.61$ and $\mathrm{C}_{\tau}=1$ ). 
According to the above model parameter study, both $\mathrm{B}_{1}$ and $\mathrm{C}_{3}$ were then increased in order to match the results at 10 bar backpressure. It is found that the second parameter set with $B_{1}=60$ and $C_{3}=1.0$ overall shows good agreement with the measurement although the penetration after $0.8 \mathrm{~ms}$ is still slightly higher than the measurements. However, this parameter set could not accurately predict the spray process at 1 bar backpressure, and the predicted penetration is much longer than the measurements due to significantly larger SMD value during the spray process at 1 bar backpressure, as shown in Figure 16 (b).

Figure 17 shows the evolutions of the spray process with different model parameter sets shown in Figure 16. At 1 bar backpressure, the second parameter set with larger values of $\mathrm{B}_{1}$ and $\mathrm{C}_{3}$ produces significantly longer penetration due to larger SMD value. At 10 bar backpressure, although the overall SMD is significantly increased for the second parameter set, the abnormal spray pattern is still observed in Figure 17 (b), which accounts for the higher penetration after 0.8 ms, as shown in Figure 16 (a).

The presented trade-off results at 1 bar and 10 bar backpressures with the current KHRT model indicate the challenges of its application to accurately model the gasoline spray and mixture formation process in modern GDI engines, especially with the multiple injection strategy, where the in-cylinder backpressure varies significantly during the injection events.

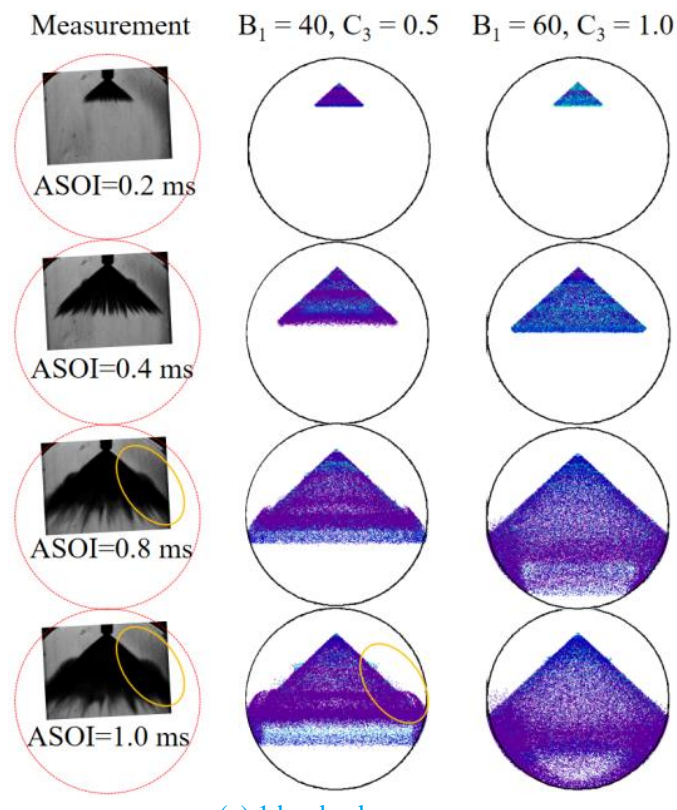

(a) 1 bar backpressure.
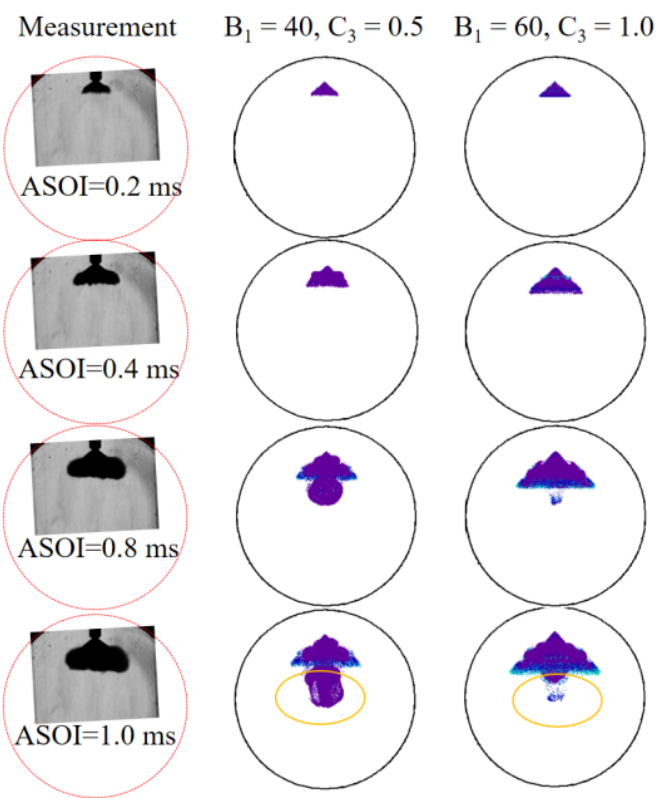

(b) 10 bar backpressure.

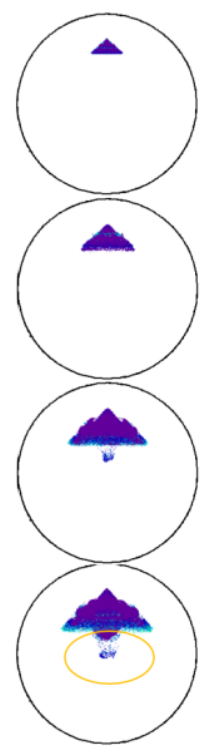

Figure 17. Comparison of the droplet distributions with different $B_{1}$ and $C_{3}$ at (a) 1 bar and (b) 10 bar backpressure (KHRT model: $\mathrm{B}_{0}=0.61$ and $\mathrm{C}_{\tau}=1$ ).

\section{Effect of model parameters of RD model}

As detailed in Numerical model section, for the RD model, the tuning parameters were $\mathrm{C}_{\mathrm{b} 1}$ and $\mathrm{C}_{\mathrm{s} 2}$, the parameters $\mathrm{C}_{\mathrm{b} 2}$ and $\mathrm{C}_{\mathrm{s} 1}$ were fixed at $\pi$ and 0.5 , respectively. Figure 18 and Figure 19 show the impact of $\mathrm{C}_{\mathrm{b} 1}$ and $\mathrm{C}_{\mathrm{s} 2}$ on the spray penetrations and SMD evolutions at 1 bar backpressure. It is found that the two tuning parameters influence the spray breakup process from the very beginning stage. As $\mathrm{C}_{\mathrm{b} 1}$ and $\mathrm{C}_{\mathrm{s} 2}$ increase, the reduction of the SMD value after the injection becomes slower, leading to longer penetrations. According to the results of the penetration and $\mathrm{SMD}$, the parameter $\mathrm{C}_{\mathrm{s} 2}$ is more effective than $\mathrm{C}_{\mathrm{b} 1}$ to adjust the spray breakup process. When $\mathrm{C}_{\mathrm{b} 1}$ reduces to 10 , the smaller SMD during the spray process produces apparent curling structures of the droplets and fuel concentration distributions at the recirculation region, as shown in Figure 19 (b). However, it should be noted that these two parameters show little impact on the final SMD value at the end of injection.

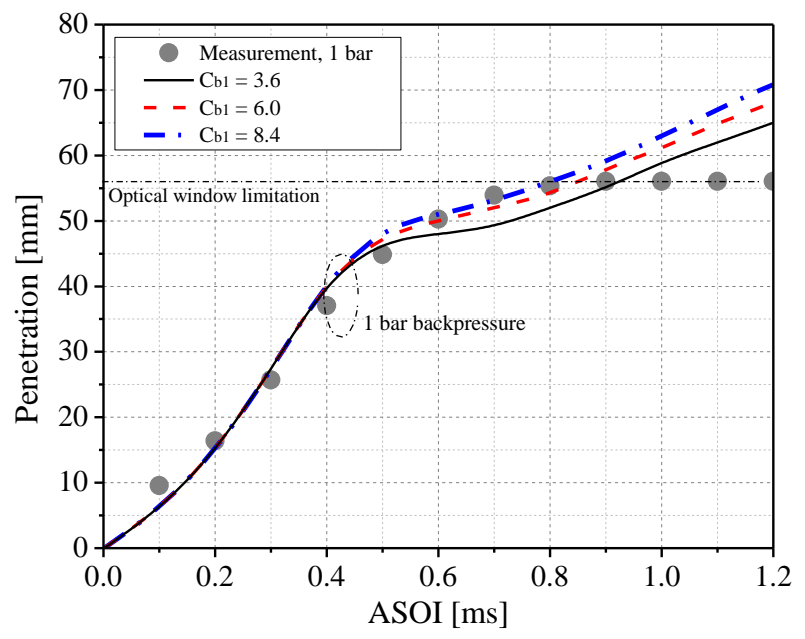

(a) Spray penetration. 


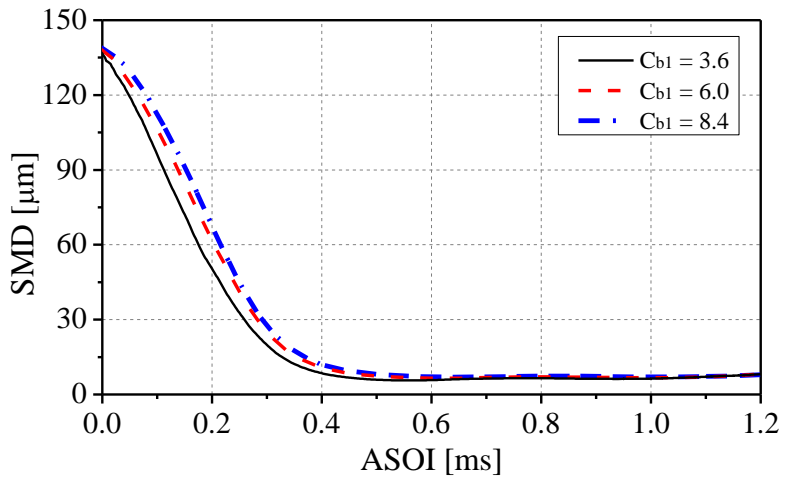

(b) Evolution of SMD with 1 bar backpressure.

Figure 18. Effect of constants $\mathrm{C}_{\mathrm{b} 1}$ on (a) spray penetration and (b) SMD with Reitz-Diwakar model, $\left(\mathrm{C}_{\mathrm{b} 2}=\pi, \mathrm{C}_{\mathrm{s} 1}=0.5\right.$ and $\left.\mathrm{C}_{\mathrm{s} 2}=20\right)$.

For the RD model, it is found in this study that the tuned parameter set $\left(C_{b 1}=8.4\right.$ and $\left.C_{s 2}=20\right)$ for 1 bar backpressure could also achieve very promising agreement at 10 bar backpressure, and the results have been shown in Figure 11.

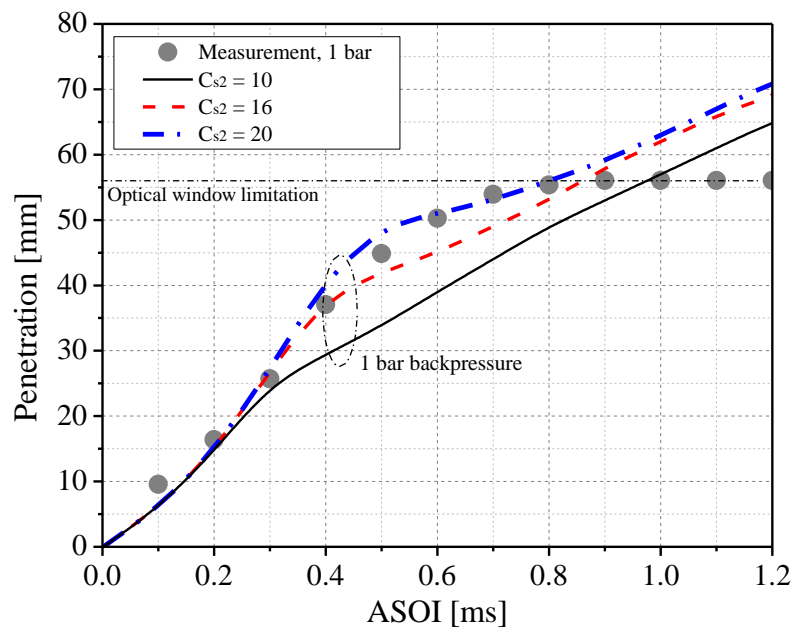

(a) Spray penetration.

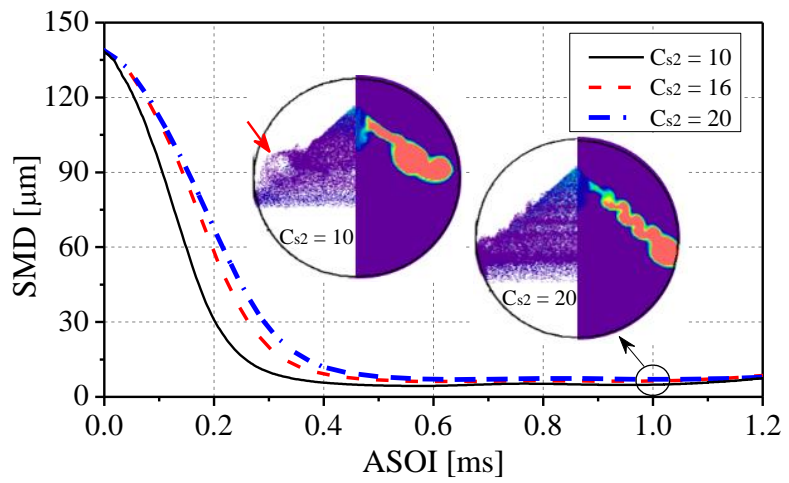

(b) Evolution of SMD with 1 bar backpressure.

Figure 19. Effect of constant $\mathrm{C}_{\mathrm{s} 2}$ on (a) spray penetration, (b) SMD and droplets and fuel concentration (0-5\%) distributions with Reitz-Diwakar model, $\left(\mathrm{C}_{\mathrm{b} 1}=8.4, \mathrm{C}_{\mathrm{b} 2}=\pi\right.$ and $\left.\mathrm{C}_{\mathrm{s} 1}=0.5\right)$.

Page 10 of 12

\section{Comparison between KHRT and RT model}

Figure 20 compares the SMD evolutions at 10 bar backpressure with the validated KHRT model and RD model. As the KHRT model could not achieve good agreements with a fixed parameter set at both backpressures, the results with two KHRT parameter sets validated respectively for 1 bar and 10 bar backpressures are all shown in Figure 20 to provide comprehensive information of the SMD evolutions with KHRT model. It is noted that the KHRT model produces much stronger breakup process at early stage (before $0.2 \mathrm{~ms}$ ) than the RD model, although the tuned KHRT model parameters specialized for 10 bar backpressure produce significantly higher SMD value than the RD model at the end of injection.

Figure 21 compares the fuel vapor concentration and velocity distributions at $0.8 \mathrm{~ms}$ with KHRT model and RD model. The scale of the fuel concentration distribution displayed in the figures ranges from 0 to $5 \%$. It is found that there is a strong downward flow motion under the injector nozzle. As the breakup process is much faster with the KHRT model, the downward flow motion transports those small droplets into the middle and leads to the abnormal spray pattern beneath the main spray umbrella. For the RD model, the weaker breakup process leads to bigger SMD at the early stage, and the injected droplets are unaffected by the downward flow. Therefore, the breakup process mainly occurs at the recirculation region and creates the fuel rich mixture at the tip of the spray jet, as shown in Figure 21 .

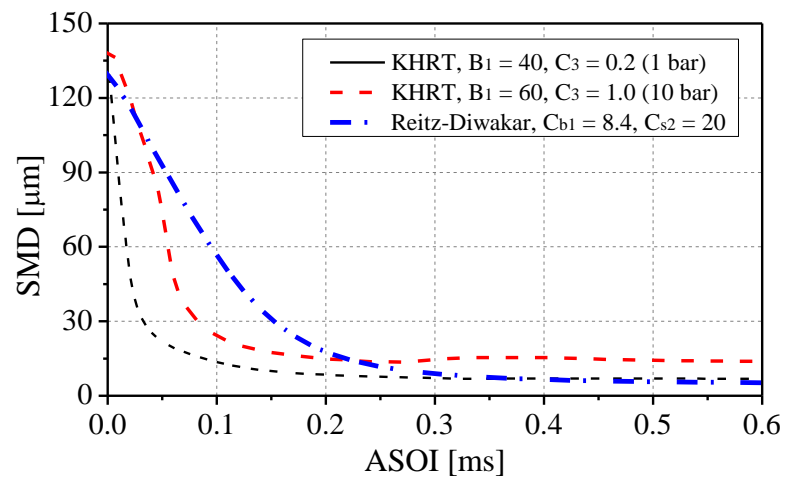

Figure 20. Comparison of the SMD at 10 bar backpressure with KHRT $\left(\mathrm{B}_{0}=\right.$ 0.61 and $\left.\mathrm{C}_{\tau}=1\right)$ and Reitz-Diwakar model $\left(\mathrm{C}_{\mathrm{b} 2}=\pi\right.$ and $\left.\mathrm{C}_{\mathrm{s} 1}=0.5\right)$.
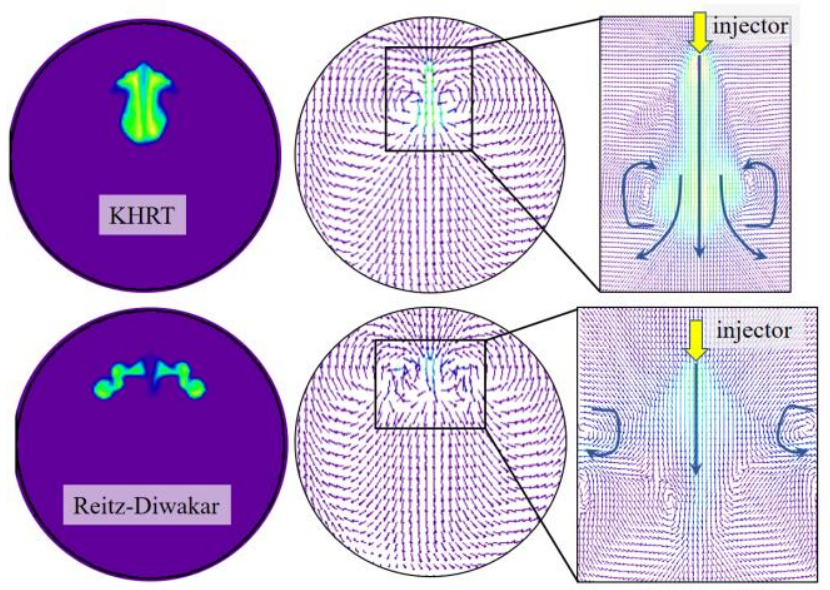

$0 \quad|||||||||||||||| \mid \quad 230 \mathrm{~m} / \mathrm{s}$

Figure 21. Comparison of fuel vapor concentration (left) and velocity distributions (right) at $0.8 \mathrm{~ms}$ at 10 bar backpressure with KHRT $\left(\mathrm{B}_{0}=0.61\right.$ and $\left.\mathrm{C}_{\tau}=1\right)$ and Reitz-Diwakar model $\left(\mathrm{C}_{\mathrm{b} 2}=\pi\right.$ and $\left.\mathrm{C}_{\mathrm{s} 1}=0.5\right)$. 
The above comparison indicates that the strong breakup of the droplets at early stage at high backpressure is believed to be the main reason accounting for the abnormal spray patters observed at $10 \mathrm{bar}$ backpressure with KHRT model. As there is no further tuning requirement for different backpressures, the RD model is found to be better in modeling the gasoline sprays from the outward-opening piezoelectric injector.

\section{Conclusions}

In order to realise accurate predictions of the gasoline spray with the outward-opening piezoelectric injector, the computational fluid dynamic (CFD) simulations of the gasoline spray with different droplet breakup models were performed in the commercial CFD software STAR-CD and validated by the corresponding measurements. The injection pressure was fixed at 180 bar, while two different backpressures ( 1 and 10 bar) were used to evaluate the robustness of the breakup models. The effects of the mesh quality, simulation timestep, breakup model parameters were investigated to clarify the overall performance of different breakup model in modeling the gasoline sprays. The findings are summarized as follows:

1. The meshes with $0.5 \mathrm{~mm}$ and $1.0 \mathrm{~mm}$ mesh size show similar penetration and spray patterns for both KHRT and RD models. In comparison, the coarse mesh with $1.5 \mathrm{~mm}$ mesh size produces much stronger breakup process at the early stage, although the final SMD at the end of injection is even larger. The simulations with the injector tip geometry show little impact on the spray process.

2. There is only slight impact of the adopted three timesteps $(0.001$, 0.0025 and $0.005 \mathrm{~ms}$ ) on the spray penetrations under 1 bar backpressure. As the back pressure increases to $10 \mathrm{bar}$, the difference of the penetrations with different timesteps become larger but the penetrations with $\Delta \mathrm{t}=0.0025 \mathrm{~ms}$ still agree well with the results with the shortest timestep $(\Delta \mathrm{t}=0.001 \mathrm{~ms})$.

3. In KHRT model, the increase of the model parameters $\mathrm{C}_{3}$ and $\mathrm{B}_{1}$ leads to weaker breakup process and longer penetration. But $\mathrm{C}_{3}$ is much more influential on the spray process than $B_{1}$. $B_{1}$ shows little impact on the initial breakup process, while $\mathrm{C}_{3}$ shows significant impact on the initial breakup process.

4. In RD model, the increase of the model parameters $\mathrm{C}_{\mathrm{b} 1}$ and $\mathrm{C}_{\mathrm{s} 2}$ leads to weaker breakup process and longer penetration. The two tuning parameters influence the spray breakup process from the very beginning stage, but the parameter $\mathrm{C}_{\mathrm{s} 2}$ is more effective than $\mathrm{C}_{\mathrm{b} 1}$ to adjust the spray breakup process. However, these two parameters show little impact on the final SMD value at the end of injection.

5. The strong breakup of the droplets at early stage at high backpressure is believed to be the main reason accounting for the abnormal spray patters observed at 10 bar backpressure with KHRT model.

6. As there is no further tuning requirement for different backpressures, the RD model is found to be better in modeling the gasoline sprays from the outward-opening piezoelectric injector.

\section{References}

[1]. Drake, M.C. and D.C. Haworth, Advanced gasoline engine development using optical diagnostics and numerical modeling. Proceedings of the Combustion Institute, 2007. 31: p. 99-124.

[2]. Reitz, R.D. and R. Diwakar, Effect of Drop Breakup on Fuel Sprays. 1986, SAE Technical Paper 860469.

[3]. REITZ, R., Modeling atomization processes in high-pressure vaporizing sprays. Atomisation and Spray Technology, 1987. 3(4): p. 309-337.

[4]. Taylor, G., The instability of liquid surfaces when accelerated in a direction perpendicular to their planes. I. Proceedings of the Royal Society of London. Series A. Mathematical and Physical Sciences, 1950. 201(1065): p. 192-196.

[5]. Beale, J.C. and R.D. Reitz, Modeling spray atomization with the Kelvin-Helmholtz/Rayleigh-Taylor hybrid model. Atomization and Sprays, 1999. 9: p. 623-650.

[6]. O'Rourke, P.J. and A.A. Amsden, The TAB method for numerical calculation of spray droplet breakup. 1987, SAE Technical Paper 872089.

[7]. Hossainpour, S. and A.R. Binesh, Investigation of fuel spray atomization in a DI heavy-duty diesel engine and comparison of various spray breakup models. Fuel, 2009. 88(5): p. 799-805.

[8]. Gao, H., et al., A modification to the WAVE breakup model for evaporating diesel spray. Applied Thermal Engineering, 2016. 108: p. $555-566$.

[9]. Ren, Y. and X. Li, Assessment and validation of liquid breakup models for high-pressure dense diesel sprays. Front. Energy, 2016. 10(2): p. 164-175.

[10]. Brulatout, J., et al., Calibration strategy of diesel-fuel spray atomization models using a design of experiment method. International Journal of Engine Research, 2016. 17(7): p. 713-731.

[11]. Han, Z., L. Fan and R.D. Reitz, Multidimensional modeling of spray atomization and air-fuel mixing in a direct-injection sparkignition engine. 1997, SAE Technical Paper 970884.

[12]. Fan, L., et al., Modeling Fuel Preparation and Stratified Combustion in a Gasoline Direct Injection Engine. 1999, SAE Technical Paper 1999-01-0175.

[13]. Kong, S.C., P.K. Senecal and R.D. Reitz, Developments in Spray Modeling in Diesel and Direct-Injection Gasoline Engines. Oil \& Gas Science and Technology, 1999. 54(2): p. 197-204.

[14]. Dempsey, A.B. and R.D. Reitz, Computational Optimization of a Heavy-Duty Compression Ignition Engine Fueled with Conventional Gasoline. 2011, SAE 2011-01-0356.

[15]. Malaguti, S., et al., MODELLING OF PRIMARY BREAKUP PROCESS OF A GASOLINE DIRECT ENGINE MULTI-HOLE SPRAY. Atomization and Sprays, 2013. 23(10): p. 861-888. 
[16]. Van Dam, N. and C. Rutland, Adapting diesel large-eddy simulation spray models for direct-injection spark-ignition applications. International Journal of Engine Research, 2016. 3(17): p. 291-315.

[17]. Wang, X., et al., Numerical Study of the Effect of Piston Shapes and Fuel Injection Strategies on In-cylinder Conditions in a PFI/GDI Gasoline Engine. SAE Int. J. Engines, 2014. 7(4).

[18]. Wang, X., H. Zhao and H. Xie, Effect of piston shapes and fuel injection strategies on stoichiometric stratified flame ignition (SFI) hybrid combustion in a PFI/DI gasoline engine by numerical simulations. Energy Conversion and Management, 2015. 98(0): p. $387-400$.

[19]. Wang, X., H. Zhao and H. Xie, Effect of dilution strategies and direct injection ratios on Stratified Flame Ignition (SFI) hybrid combustion in a PFI/DI gasoline engine. Applied Energy, 2016. 165: p. $801-814$.

[20]. Bonatesta, F., et al. Application of Computational Fluid Dynamics to Explore the Sources of Soot Formation in a Gasoline Direct Injection Engine. 2014: SAE Technical Paper 2014-01-2569.

[21]. Sim, J., et al., Spray Modeling for Outwardly Opening HollowCone Injector. 2016, SAE Technical Paper 2016-01-0844.

[22]. CD-adapco, STAR Methodology, STAR-CD VERSION 4.22, 2014. 2014.

[23]. Jones, W.P., Prediction methods for turbulent flames, in Prediction Methods for Turbulent Flow, W. Kollmann, W. Kollmann^Editors. 1980, Hemisphere: Washington, D.C. p. 1-45.

[24]. Angelberger, C., T. Poinsot and B. Delhay, Improving NearWall Combustion and Wall Heat Transfer Modeling in SI Engine Computations. 1997, SAE Technical Paper 972881.

[25]. Lefebvre, A., Atomization and sprays. Vol. 1040. 1988: CRC press.
[26]. El Wakil, M.M., O.A. Uyehara and P.S. Myers, A theoretical investigation of the heating-up period of injected fuel droplets vaporizing in air. 1954

[27]. Ranz, W.E. and W.R. Marshall, Evaporation from drops. Chem. Eng. Prog, 1952. 48(3): p. 141-146.

[28]. Bai, C. and A.D. Gosman, Development of Methodology for Spray Impingement Simulation. 1995, SAE Technical Paper 950283.

[29]. Patterson, M.A. and R.D. Reitz, Modeling the effects of fuel spray characteristics on diesel engine combustion and emission. 1998, SAE Technical Paper 980131.

[30]. Senecal, P.K., et al., A new parallel cut-cell Cartesian CFD code for rapid grid generation applied to in-cylinder diesel engine simulations. 2007, SAE Technical Paper 2007-01-0159.

\section{Contact Information}

Dr. Xinyan Wang

xinyan.wang@brunel.ac.uk

Centre for Advanced Powertrain and Fuel Research

Brunel University London, UK

UB8 3PH

\section{Acknowledgments}

The authors gratefully acknowledge the financial support by the Engineering and Physical Sciences Research Council (EPSRC). The data of this paper can be accessed from the Brunel University London data archive, figshare at https://doi.org/10.17633/rd.brunel.5830677.

We also want to acknowledge the State Key Laboratory of Engines (SKLE), Tianjin University for providing the spray measurements of the injector. 